\title{
SPMULHERES EM DADOS
}

\author{
Maria Cecília Comegno
}

\begin{abstract}
Resumo: A conquista de direitos formais para as mulheres parece diluída na persistência de práticas discriminatórias tanto no espaço público como no privado. A informação é um dos elementos indispensáveis ao exercício da plena cidadania e ferramenta para a formulação de políticas públicas. O artigo trata de um sistema de informações sobre temas estruturantes na vida das mulheres no Estado de São Paulo que permite diagnosticar diversos processos em curso nas relações de gênero.

Palavras-chave: políticas públicas; gênero; mulheres paulistas.

Abstract: The achievement of formal rights by women is diluted by the persistence of discriminatory practices both in the public and private spheres. Information is one of the essential elements towards full social participation and is a tool in the formulation of public policy. This text discusses a system of information on the state of women in São Paulo State and permits a diagnosis of the diverse processes underway in gender relations. Key words: public policy; gender; women of São Paulo State.
\end{abstract}

$\mathrm{N}$ as últimas décadas, registraram-se avanços significativos nas relações entre homens e mulheres, mas persistem ainda práticas discriminatórias, tanto no espaço público como no privado. Essas práticas foram mundialmente reconhecidas pela necessidade de ampliação do conceito de direitos humanos, que adquiriram significado e alcance novos quando a IV Conferência Mundial das Nações Unidas sobre a Mulher, realizada em Pequim (1995), declara que "os direitos humanos das mulheres e das meninas são parte inalienável, integrante e indivisível dos direitos universais". Essa concepção foi incorporada aos tratados e acordos assinados nos anos 90 entre nações, com efeitos diretos no âmbito interno dos países signatários das convenções, como é o caso do Brasil, colocando novos desafios e oportunidades para os órgãos institucionais de direitos da mulher no que diz respeito à definição de políticas públicas de gênero. Nesse sentido, um dos mais importantes instrumentos que introduz essa visão é a Convenção sobre a Eliminação de Todas as Formas de Discriminação contra a Mulher - Cedaw, ratificada pelo Brasil em 1984 e promulgada pelo Decreto $\mathrm{n}^{\circ} 4.377$, de 13 de setembro de 2002 .
Cabe, ainda, ressaltar que quando se focaliza a questão das desigualdades sociais as soluções tornam-se ainda mais problemáticas, uma vez que a capacidade dos Estados de sustentar políticas de bem-estar social e, desse modo, garantir a universalidade dos direitos sociais, está altamente comprometida com a reestruturação do sistema econômico mundial, das economias nacionais e do gasto público. Acresce-se a esse quadro a expansão da população economicamente ativa, uma das mais importantes transformações sociais ocorridas no país desde os anos 70, que deriva das mudanças demográficas, culturais e sociais manifestadas no Brasil e tem como base a necessidade econômica e as oportunidades oferecidas, afetando em particular esse contingente populacional.

A criação legal do Conselho Estadual da Condição Feminina-CECF, em 1986, pelo governo do Estado de São Paulo, mas que por decreto funcionava desde 1983, iniciou o processo de formulação e implementação de políticas públicas dirigidas às mulheres, com base na ação conjunta de entidades femininas e de órgãos executores. À medida que o CECF ampliava sua área de atuação, com a multiplicação dos conselhos municipais, e crescia a demanda por subsídios para a aplicação de políticas locais, 
tornou-se evidente a carência de informações sistematizadas sobre a situação das mulheres paulistas. Apesar de algumas iniciativas pontuais, persistia a dispersão e a fragmentação das informações.

A Fundação Seade, desde 1993, trabalha em parceria com o Conselho para suprir tal carência. Nesse mesmo ano, foi firmado entre ambos um convênio de prestação de serviços técnicos especializados de produção de dados e indicadores sobre a mulher paulista. E desde 1996, valendo-se de um contrato de cooperação técnica ajustado com a Agência Canadense para o Desenvolvimento Internacional/Fundo para Eqüidade de Gênero, a Fundação Seade vem trabalhando para a produção de indicadores sobre a mulher e o mercado de trabalho na Região Metropolitana de São Paulo.

Em 2000, essa parceria se repetiu no Programa de Políticas Públicas, com apoio da Fapesp, para produzir um sistema de informações que permite diagnosticar a situação da mulher paulista, e, ao mesmo tempo, propiciar a formulação de políticas e programas públicos pela ótica de gênero.

Intitulado SPMulheres em Dados e formatado em padrão Internet, esse produto acolhe uma antiga reivindicação do CECF: dispor de estatísticas quanto à situação da mulher no Estado em suas áreas prioritárias de atuação.

O projeto inscreve-se no campo do fortalecimento dos mecanismos de promoção da mulher, para integrar suas demandas nos programas governamentais e ao mesmo tempo identificar os aspectos críticos na trajetória da construção das políticas de gênero no Estado de São Paulo.

A concepção da parceria apresentada neste projeto teve, entre outros objetivos, a introdução de uma alteração qualitativa e inovadora nos trabalhos do CECF, pois, ao se apropriar de um sistema de informações selecionadas com base em seu centro de interesse, passa ele a ter um diagnóstico da situação da mulher no Estado de São Paulo, o que lhe permite propor políticas públicas prioritárias e articuladas, sob a perspectiva de gênero, como também atender a seus diferentes usuários - secretarias estaduais e municipais, conselhos municipais da condição feminina, entidades de mulheres, etc.

\section{ABORDAGENS TEMÁTICAS DIFERENCIADAS}

O ponto de partida para estabelecer o referencial temático do SPMulheres em Dados foi a leitura de diversos documentos, cujos signatários comprometeram-se com a luta pela implementação da Plataforma de Ação aprovada na IV Conferência Mundial das Mulheres. ${ }^{1}$

Procurou-se, assim, voltar-se para temas que se referem às áreas prioritárias de atuação do CECF, sobretudo seus aspectos que incorporam a perspectiva de gênero como fator transversal em suas respectivas ações programáticas. Foram, então, selecionados os seguintes temas: demografia, saúde e direitos reprodutivos, educação, trabalho, violência e participação política. Essa escolha deveu-se, também, ao fato de eles serem estruturantes na vida das mulheres e abrirem caminhos para mudanças necessárias. É preciso salientar que a complexidade que envolve a questão dos direitos humanos relativos à mulher abrange um campo de preocupações muito mais amplo do que o proposto neste projeto, como é o caso, por exemplo, dos efeitos da globalização sobre a vida das mulheres nas áreas ambiental, cultural e de acesso a novas tecnologias de informação e comunicações. De toda forma, esses temas ainda estão praticamente ausentes da agenda do movimento de mulheres como também da agenda de pesquisas de gênero - o que demonstra a baixa capacidade da sociedade civil e do Estado em pautar tais demandas e propor ações.

A problemática das relações sociais de sexo exige uma leitura da sociedade de tal forma que desenvolva a percepção da hierarquia entre masculino e feminino e que essas relações não sejam neutras. A relação social de sexo ou a noção de gênero é um conceito recente que ainda apresenta inúmeras controvérsias, mas, graças à produção acadêmica e à emergência dos movimentos feministas, após os anos 70, acumulou-se uma série de abordagens conceituais fundamentais que orientam a leitura do cotidiano das mulheres.

\section{Perfil Demográfico}

As estatísticas demográficas constituem elemento de diagnóstico importante para identificar as desigualdades entre os sexos. Embora a variável sexo esteja presente nas pesquisas e nos recenseamentos, não necessariamente revela as relações socialmente valorizadas e prescritas entre homens e mulheres que permitam, por sua vez, compreender os mecanismos que determinarão os diferentes comportamentos.

Em sua reflexão quanto às metodologias quantitativas em pesquisas sobre relações de gênero, Bruschini (1992: 291) assinala que uma "abordagem feminista é o exame crítico das relações sociais tendo em vista a existência de um recorte de gênero, que também define desigualdades 
sociais". Não se trata, portanto, de estudo tradicional sobre as mulheres, e a diferença estaria no exame das relações de gênero e na busca de uma resposta à opressão da mulher pelo gênero. Em análises demográficas, é importante o conhecimento de quem decide o quê, tanto em relação à fecundidade, à saúde como à migração, mas as estatísticas são incapazes de responder corretamente a essas questões com perguntas individuais e "fechadas".

Outros autores (Moreira, 1994; Goldani, 1994-2000; Alves, 1994) têm assinalado as dificuldades para incorporar nos determinantes da fecundidade (ou de outra variável) as relações de gênero, utilizando dados censitários e pesquisas demográficas e de saúde, devido, basicamente, à ausência de informações diretas capazes de consubstanciá-las. Para dimensionar todos os aspectos da discriminação feminina, Goldani (2000) incorpora a seu estudo tanto as práticas como as representações individuais, selecionando algumas áreas específicas para captar os indicadores de (des)igualdade de gênero nas famílias: a estrutura diferencial da divisão de trabalho de produção e reprodução na família, as formas de divisão do poder e tomadas de decisão pelos membros da família, a sexualidade e os comportamentos sexuais, redes de apoios familiares, violência doméstica, representações de casamento, filhos e família. Esse estudo sinaliza a complexidade de se construir e obter indicadores adequados para estudos de gênero; na prática, aproximações e adequações são realizadas utilizando-se os dados e as fontes de informação disponíveis.

Apesar dessas considerações, as informações demográficas são importantes instrumentos para o conhecimento do perfil das populações feminina e masculina, assim como para avaliar sua modificação ao longo do tempo, e é um indicador da persistência ou não da desigualdade entre homens e mulheres. Principalmente para o planejamento e a elaboração de políticas públicas referentes ao segmento feminino, elas permitem quantificar as populações-alvo e caracterizar as formas de desigualdade de gênero que emergem, sobretudo, quanto aos seus efeitos sobre a saúde das mulheres e para os quais é preciso elaborar intervenções.

De fato, nas últimas décadas, observam-se modificações no perfil demográfico das mulheres paulistas que acarretam novas demandas de políticas voltadas para esse segmento populacional. Elas são principalmente urbanas, adultas-jovens, diminuíram o tamanho de suas famílias e várias declaram ser chefes das mesmas.

Ao tratar das especificidades da mulher, é fundamental considerar as desigualdades raciais e de gênero como resultado do processo histórico que conformou a sociedade brasileira. Estudiosos produziram ampla literatura mostrando que, no Brasil, as mulheres são mais discriminadas racialmente do que os homens, o que pode ser traduzido em acessos e oportunidades desiguais, gerando formas freqüentemente perversas de exclusão.

Quando se faz o recorte etário, a população adolescente-jovem constitui uma das maiores preocupações de sociedades, governos e organismos internacionais, visto que se encontra entre os grupos sociais mais atingidos pelas rápidas e profundas mudanças da pós-modernidade. Para este segmento, destacam-se problemas específicos da gravidez e maternidade precoce, que estariam limitando suas oportunidades de inserção social numa sociedade competitiva.

As mudanças projetadas na pirâmide demográfica também indicam preocupações sobre o envelhecimento populacional e colocam a questão da feminização da velhice, exigindo um olhar atento às relações de gênero.

Existem, ainda, outros problemas relacionados com o estado conjugal das mulheres, tais como: casamento em idade sistematicamente inferior à do homem, aceito e mesmo imposto cultural e socialmente no país; casamento precoce, que muitas vezes alija a mulher do trabalho fora do lar; viuvez, divórcio e separação que, em geral, afetam mais a mulher. Nas zonas urbanas, e em especial nas áreas metropolitanas, constata-se um número crescente de mulheres que vivem sem cônjuge e com filhos ou simplesmente sozinhas.

\section{Saúde e Direitos Reprodutivos}

$\mathrm{Na}$ área da saúde, a literatura registra diferenciais entre homens e mulheres com relação às seguintes dimensões: necessidades especiais de atenção à saúde; riscos específicos ligados a atividades ou tarefas definidas como masculinas ou femininas; percepção da doença; condutas de busca de serviços de saúde; grau de acesso e controle exercido sobre os recursos básicos de atenção a saúde, tanto no nível intrafamiliar como público; e, no nível macrossocial, prioridades na distribuição de recursos públicos destinados à saúde e investigação dos problemas que afetam diferente ou exclusivamente um dos sexos (Gomez Gomez, 1993).

Nesse sentido, uma análise de gênero reconhece o impacto específico que os problemas de saúde têm em homens e mulheres e procura entender de que modo, pelas relações e pela ideologia de gênero vigentes, são diferen- 
tes as experiências/ percepções/ necessidades/ papéis de homens e mulheres com respeito à saúde e seu acesso aos recursos e benefícios dela própria e ainda como as instituições, estatais ou privadas, encarregadas dos serviços de saúde, encaram o processo de reforçar ou questionar os papéis atribuídos socialmente a homens e mulheres (Casas et al., 1998).

Com a ampliação dos movimentos de mulheres e as resoluções adotadas pelas diferentes conferências mundiais de que os direitos reprodutivos são reconhecidos como direitos humanos, as relações de gênero incorporaram-se às pautas de debate dos serviços de saúde, propondo alteração no eixo do atendimento, que passa a trabalhar com o conceito de saúde integral da mulher em todas as fases da vida, não só no período reprodutivo. Embora esse conceito tenha sido incorporado, desde 1986, como política pelo Ministério da Saúde, com o Programa de Atenção Integral à Saúde da Mulher - Paism, "existem ainda grandes distorções e desigualdade de gênero no atendimento à saúde sexual e reprodutiva, e a qualidade do atendimento ainda deixa muito a desejar" (Galvão; Diaz, 1999: 17).

A saúde reprodutiva é conceituada como um estado de completo bem-estar físico, mental e social e não apenas a ausência de doenças ou incapacidades, em todas as questões relacionadas ao sistema reprodutivo.

É preocupante a precocidade cada vez maior do início da vida sexual, detectada pelo aumento da gestação na adolescência (Fundação Seade, 1998a) e que apresenta grandes riscos, em comparação a outros grupos etários.

O aumento da esperança de vida, especialmente para as mulheres, deve ser acompanhado por uma maior qualidade nas condições de saúde da população idosa, o que significa assegurar orientação adequada e prevenção de doenças decorrentes do envelhecimento, além da garantia de acesso aos serviços de saúde com atendimento especializado.

Um estudo de gênero da morbimortalidade implica necessariamente a análise dos diferenciais entre os sexos por causas específicas. No Brasil, estima-se que o câncer do colo do útero seja o segundo mais comum na população feminina, representando $15 \%$ de todos os tumores malignos em mulheres, superado apenas pelo de mama.

Embora não existam estatísticas nacionais confiáveis, foram realizadas várias investigações sobre a mortalidade materna. No Brasil, o risco de morte ou de lesões permanentes em conseqüência de um aborto clandestino depende, em última instância, não só da clandestinidade em si, mas do poder aquisitivo da mulher (Bacha; Grassioto,
1994). Mulheres pobres, cuja qualidade de vida já está marcadamente prejudicada pela dificuldade de acesso à educação, à alimentação e aos cuidados básicos de saúde, são as que engrossam as estatísticas de mortalidade por aborto.

É considerável o número de doenças transmitidas sexualmente, representando um grave problema por suas repercussões médicas, sociais e econômicas. Além das Doenças Sexualmente Transmitidas - DSTs, existe ainda a alta incidência de infecção pelo vírus HIV em mulheres, e a vulnerabilidade depende de inúmeros determinantes sociais, remetendo às formas como homens e mulheres relacionam-se em nossa sociedade (Simões Barbosa, 1999).

Pouco se conhece acerca do impacto do trabalho sobre a saúde da mulher. Pesquisadores esclarecem que a aplicação do conceito de gênero contribui e alarga a compreensão do fenômeno do processo saúde-doença ao introduzir "a dimensão de poder crivada pela desigualdade sexual para explicar os diferentes impactos que a exposição aos mesmos riscos químicos, ergonômicos e psíquicos nos locais de trabalho provocam no homem e na mulher" (Oliveira; Barreto, 1997).

No Brasil, também não existe a dimensão exata do fenômeno da violência doméstica, conjugal e intrafamiliar na saúde das mulheres. Este ainda é um fato pouco esclarecido, em razão do silêncio feminino e da ausência de escuta social. Apesar da implantação da Norma Técnica do Ministério da Saúde para a "Prevenção e Tratamento dos Agravos Resultantes da Violência Sexual contra Mulheres e Adolescentes" (1998), os serviços de saúde não estão preparados para reconhecer a violência de gênero como causa dos problemas de saúde das mulheres, especialmente no atendimento médico.

O recorte por grupos raciais também é de suma importância nos estudos de saúde, uma vez que além de predisposições de ordem biológica, fatores ligados a condições socioeconômicas e padrões culturais podem trazer uma vulnerabilidade maior em relação a determinadas doenças.

\section{Situação Educacional}

No Brasil, como em vários países do mundo, menos ou mais desenvolvidos, as mulheres - desde a escola primária até a universidade - apresentam melhores resultados escolares que os homens. De fato, o combate à desigualdade envolve a oferta de serviços sociais básicos, públicos e de caráter universal como mostra o exemplo da edu- 
cação pública em que as mulheres são as maiores beneficiárias da universalização do acesso ao ensino fundamental. No entanto, o paradoxo permanece: se as mulheres apresentam melhor rendimento escolar, por que os homens, com o mesmo nível educacional que as mulheres, recebem melhor salário no mercado de trabalho?

As discussões relevantes na temática "mulher e educação" convergem para os seguintes pontos:

- a educação da mulher como importante fator de mudança sociocultural;

- a ampliação do leque de escolha do curso superior avançando para áreas tradicionalmente masculinas; e

- a problemática das diferenças e significados do desempenho escolar de acordo com o sexo.

A educação da mulher é motivo de preocupação para determinados organismos internacionais, já que seu avanço é um fator de mudança sociocultural. Todos recomendam eliminar os estereótipos de gênero das práticas, matérias, materiais, currículos e instalações educacionais; e eliminar as barreiras que impedem o acesso à educação de adolescentes grávidas ou mães jovens à educação.

Há consenso de que investimentos na educação da mulher exercem importante papel social, contribuindo para a melhoria de suas condições de vida ao dotá-la de bagagem cultural que lhe permite agir positivamente na busca de melhores oportunidades.

A oferta de cursos superiores, tradicionalmente masculinos, ganha força em um cenário de crescentes inovações tecnológicas, em que exigências por novas competências e habilidades colocam-se ao cidadão, superando cada vez mais restrições definidas a priori, tais como aquelas associadas ao sexo.

Quanto às diferenças de desempenho escolar observadas entre os dois sexos, Madeira (1996) observa que desde a metade dos anos 70 os indicadores educacionais são ligeiramente favoráveis às meninas, o que requer novas abordagens para identificar as desigualdades existentes. No caso do Brasil, é fundamental agregar, além do recorte de gênero, o de raça para visualizar o quadro de desigualdade existente, uma vez que pesquisas indicam diferenças nas taxas de analfabetismo e número de anos de estudo entre brancos e negros.

Ainda que relevantes, essas discussões, não podem caminhar isoladamente, já que o melhor desempenho da população feminina em relação à população masculina estaria longe de representar uma conquista (Madeira, 1996). Ou seja, as jovens, sobretudo as de baixa renda, ainda que sofram menos reprovações que os meninos de mesma condição social, nem por isso deixam de ser atingidas pelos reveses do sistema em face da tarefa de promover a formação básica para a cidadania. E, mais grave, as explicações para o insucesso feminino (Abramowicz, 1991) mostram-se diferenciadas daquelas consideradas para o segmento masculino. Para este segmento, enquanto a retenção é vista e, em alguma medida, aceita como "coisa de moleque", a interpretação para o mesmo fenômeno entre as meninas é bem menos condescendente, prevalecendo colocações que reacendem velhos preconceitos relativos à capacidade intelectual da mulher, influenciando negativamente sobre sua auto-estima e sugerindo uma inserção social restrita.

Por fim, perpassando as discussões mencionadas, as explorações relativas à articulação mulher/educação remetem a uma outra, de natureza diferente, mas nem por isso de menor importância, que decorre da correlação positiva existente entre a escolaridade das mães e os elevados níveis médios de anos de estudo e a alta freqüência à escola dos filhos, fenômeno regular, que ocorre com os alunos dos ensinos fundamental e médio. Esta recorrência sugere a idéia de que mudanças acentuadas nos níveis de escolaridade da população também dependem de ciclos geracionais, isto é, da emergência de gerações de mães instruídas, demandando e facilitando a aquisição de nível de escolaridade mais elevado para seus filhos (Fundação Seade, 1998b).

Nessa perspectiva, ressalta-se a importância dos equipamentos coletivos como as instituições de educação infantil - creches e pré-escolas -, para que os filhos não constituam entraves ao engajamento da mulher no mercado de trabalho, compartilhando, assim, com toda a sociedade, o direito à reprodução, sem punir a mulher no que se refere à descontinuidade no trabalho e conseqüente reflexo em sua qualificação, competitividade e qualidade de vida.

\section{Inserção no Mercado de Trabalho}

O trabalho, como principal atividade humana, é um dos fundamentos da organização social, tanto no nível econômico como nas relações entre grupos sociais. Por sua vez, a noção de divisão do trabalho, de acordo com o sexo, constitui uma das dimensões relevantes da divisão social do trabalho e, conseqüentemente, da organização e do funcionamento de cada sociedade (Hirata; Kergoat, 1994). A relação entre divisão social e divisão sexual do traba- 
lho, entretanto, não é automática, porque não está condicionada unicamente às formas de produção ou de relações do trabalho, mas é influenciada também pelas representações e padrões de conduta determinados para cada sexo, ou seja, pelas relações de gênero criadas no âmbito da família, cultura, religião, etc.

Ao entrar no mercado de trabalho, as mulheres o fazem em condições absolutamente desiguais, porque sua existência e habilitação para o trabalho são vistas pelo filtro da imagem do gênero dominante na consciência dos membros da sociedade, que até parece natural, isto é, biológica. Para elas estão reservadas, primordialmente, funções associadas à vida privada, ao cuidado com a família e, por isso, sua inserção profissional seria uma extensão da vida doméstica, sobretudo nas atividades de cuidado com crianças e adolescentes (professoras), ou adultos (enfermeiras, psicólogas, terapeutas, etc.), e de manutenção de espaços domésticos ou empresariais (empregadas domésticas, prestadoras de serviços de limpeza, etc.). Diversas análises sobre as mulheres no mercado de trabalho indicam uma tendência à conformação de nichos ocupacionais, espaços de inserção predominantemente femininos, criados pela sobreposição de alguns processos sociais ou pela dinâmica do mercado de trabalho (Costa, 1996; Leone, 1998).

As diferenças são visíveis ao se contrapor a remuneração de mulheres e homens, em qualquer momento da história brasileira, sem dúvida um exercício de demonstração da inferioridade do primeiro segmento e a existência de discriminação que resultam da interação de vários fatores, cujas causas devem ser identificadas (Alves et al., 1996; Fundação Seade, 1997; Bruschini, 1998).

Um dos aspectos está diretamente relacionado a políticas de enfrentamento da pobreza. É certo que um dos principais determinantes da pobreza seja a baixa disponibilidade de renda per capita, ${ }^{2}$ e a participação das mulheres na força de trabalho pode ser um importante fator de redução desse fenômeno. A inserção das mulheres no mercado de trabalho, sejam cônjuges ou filhas, agrega uma fonte adicional de renda à família, e quanto maiores e melhores suas oportunidades, maior impacto terão sobre as condições de vida familiares. Quando a mulher é chefe, essa relação se aprofunda ainda mais, pois sua capacidade de geração de renda é fundamental para compor o rendimento familiar.

Quanto à situação da mulher brasileira, de modo particular da que vive no Estado de São Paulo, os estudos acusam sua crescente participação no mercado de trabalho (Bruschini, 1998; Wajnman; Rios Neto, 2000; Fundação
Seade, 2002), embora também cresça o contingente das que permanecem desempregadas e o das que têm obtido trabalho em condições menos favoráveis no contexto da reestruturação econômica, não apenas pela segmentação do mercado mas pelo tipo de remuneração e de condições de trabalho (Segnini, 2000).

A análise de programas de intermediação de mão-deobra e capacitação profissional (Fundação Seade, 2000) mostra que as mulheres têm oportunidades bastante expressivas de acesso a esses programas e a outros de caráter variável, como microcrédito e frentes de trabalho nas regiões metropolitanas.

Diferentemente de outros países, mesmo latino-americanos, essa situação ocorre em um contexto de políticas de acesso universal que apenas de forma secundária privilegia a inserção feminina, mas apesar de esses programas não terem sido desenhados explicitamente com a perspectiva de gênero, o certo é que obtiveram como resultado grande participação feminina.

\section{Violência Contra a Mulher}

Os estudos sobre violência contra a mulher, tradicionalmente, têm enfatizado duas ordens de fenômenos: a violência sexual e a conjugal. Esses tipos de violência singularizaram-se, destacaram-se da massa indiferenciada de atos violentos, adquiriram face própria e, desse modo, politizaram-se (Heilborn, 1987).

A Convenção Interamericana para Prevenir, Punir e Erradicar a Violência contra a Mulher, promulgada pela Assembléia Geral da Organização dos Estados Americanos, em 1994, e ratificada pelo Brasil em 1995, introduziu conceitos importantes, com vista em melhorar a proteção legal dos direitos das mulheres. Entre esses, destacam-se o reconhecimento da categoria "gênero", a noção de "direito a uma vida livre de violência", a visibilidade da violência sexual e psicológica e a consideração dos âmbitos público e privado como espaços de ocorrência de atos violentos contra mulheres.

Além dessas preocupações mais amplas, vários movimentos sociais voltados para a questão da violência contra a mulher também enfatizam temas pontuais, relacionados a mulheres que pertencem a grupos que as colocam em situação de maior fragilidade: presidiárias, negras, pobres, etc.

Da mesma forma, o tema violência contra a mulher firmou-se como um "problema de gênero", configurando-se como “(...) um conjunto de papéis que são conferidos à 
mulher como obrigatórios e dos quais ela não pode afastar-se, sob pena de perder as condicionantes que justificam o 'respeito' que a sociedade lhe deve dedicar" (Pimental et al., 1998).

Embora haja avanços legais alcançados nas últimas décadas, o que se tornou visível ao sistema de justiça foram questões incorporadas em debates mais amplos, relacionadas aos direitos da cidadania. Permanece invisível ao sistema boa parte da violência praticada contra a mulher, seja porque não é por ele percebida como problema, pois escapa a suas categorias e tipificações (especialmente, lesões de natureza psicossocial), seja porque as próprias vítimas se calam perante os poderes instituídos, tanto por medo de vingança de seus agressores, quanto por desacreditarem nesses poderes como instrumentos legítimos e eficazes de resolução de conflitos.

Não obstante a criação das Delegacias de Defesa da Mulher - DDM tenha facilitado o registro de queixas, continuam havendo graves empecilhos para apresentar quadros mais detalhados e amplos e ao mesmo tempo capazes de caracterizar a complexidade das violências praticadas contra as mulheres.

\section{Participação Política}

O tema da relação das mulheres com o poder remete, prioritariamente, à questão da baixa presença feminina nas instâncias de representação política, apesar de o Brasil estar entre os primeiros países da América Latina a instituir, em 1932, o direito da mulher de votar e ser votada.

Fatores estruturais e culturais concorrem para o reduzido acesso da mulher ao poder: desigual divisão do trabalho, atitudes preconceituosas conscientes ou inconscientes contra a mulher, incorporadas até por ela, hábitos tradicionais e práticas discriminatórias presentes nos partidos políticos e nas estruturas governamentais, estereótipos sociais negativos sobre funções da mulher e do homem, reforçando a tendência de as funções políticas permanecerem no domínio masculino. As responsabilidades com a família e a criação dos filhos trazem um elevado custo para as mulheres que aspiram a cargos públicos e conservá-las significa um fator de desestímulo a futuras candidaturas.

Organismos e fóruns internacionais sobre a mulher vêm reafirmando a necessidade de se adotarem medidas que visem a compensar a discriminação e acelerar a igualdade no plano político entre homens e mulheres. ${ }^{3}$ Dessa forma, a luta das mulheres pela ampliação de seus direitos de participação política adquire uma perspectiva própria com o deslocamento das prioridades do movimento feminista: uma postura de denúncia dos mecanismos geradores da exclusão e de crítica da natureza do Estado presente até os anos 80, para formulação de políticas que visam a ampliação dos espaços da mulher no poder (Oliveira Araújo, 1999).

É nesse cenário que surge, nas últimas décadas do século XX, a formulação e a adoção, em diferentes partes do mundo, da política de cotas para mulheres ou de cotas por sexo a fim de reequilibrar a participação das mulheres na política.

Embora em diversos países essa política tenha sido adotada ao mesmo tempo em diferentes instâncias privadas e públicas, no Brasil, ela teve início nos partidos políticos e sindicatos e consolidou-se pela legislação eleitoral, com a Lei $\mathrm{n}^{\circ}$ 9.100/95, quando foi aprovada a regulamentação para as eleições de 1996, assegurando uma cota mínima, em cada partido ou coligação, de $20 \%$ de candidaturas de mulheres para as Câmaras Municipais. A Lei no 9.504/97 ampliou essa reserva para um mínimo de $30 \%$ e máximo de $70 \%$ para os candidatos de cada sexo a todas as instâncias legislativas, eleitos pelo voto proporcional nas eleições de 1998. No entanto, as disposições transitórias da Lei n ${ }^{0}$ 9.504/97 que regulamentaram as eleições de 1998 introduzem uma mudança significativa ao estabelecer proporcionalidade mínima de $25 \%$ e máxima de $75 \%$ para a candidatura de qualquer dos sexos. Como observa Malheiros (2000), deixa de ser uma medida compensatória para as mulheres e passa a ser uma medida de redistribuição de poder, a partir de parâmetros mínimos de eqüidade e universalidade.

Apoiada em experiências de países europeus, essa legislação abre um espaço de intervenção que nem os partidos políticos e nem as próprias mulheres estão preparados para ocupar, levando a bancada feminina e diversas entidades governamentais e não-governamentais a introduzir em suas agendas a preparação e capacitação de mulheres para a disputa de cargos eletivos.

Mesmo não correspondendo à capacidade de liderança exercida pelas mulheres em organizações comunitárias e não-governamentais, a questão da participação da mulher nas estruturas de poder, e particularmente no poder legislativo local ou nacional, ganhou centralidade e prioridade na agenda dos órgãos oficiais formuladores de políticas públicas, não apenas pela aprovação de leis regulamentando cotas para as mulheres nas candidaturas partidárias e criando a oportunidade de acompanhar sua 
eficácia, mas também pela existência de um hiato importante entre a conquista formal dos direitos e a possibilidade de seu desfrute real.

Nesse sentido, a política de cotas, efetivando-se em um espaço caracterizado como atividade estruturada, ao menos nos períodos eleitorais, apresenta-se como uma política pública institucional que pode ser analisada com base nas características de seu processo e dos resultados obtidos com base em indicadores objetivos.

\section{Metodologia de Construção do Banco de Dados}

Com vista em produzir indicadores de gênero comparáveis, partiu-se de uma avaliação do que é proposto pelas instituições públicas produtoras de dados estatísticos, centros de pesquisa universitários, organizações governamentais nacionais e internacionais. Merece destaque a proposta - Uso de Indicadores de Gênero no Desenvolvimento de Políticas Públicas - desenvolvida pela Unidade Mulher e Desenvolvimento/Divisão de Estatísticas da Comissão Econômica para o Desenvolvimento da América Latina e Caribe - Cepal (2001), em maio de 1999, por ter como base a seleção das principais dimensões em que se expressam as desigualdades de gênero, identificadas pelo "Programa de Acción Regional para las Mujeres de América Latina y el Caribe, 1995 - 2001 y la Plataforma de Acción de Beijing", a comparação entre países e a validada pela Cepal e organismos internacionais especializados. Ao contrapor a proposta da Cepal ao elenco de indicadores usualmente utilizados no Brasil, evidenciaramse dois tipos de problemas: inadequação de alguns indicadores às situações específicas vivenciadas pelas mulheres brasileiras, demandando, portanto, o desenvolvimento de novas medidas; e a limitação das informações disponíveis para a captação da dimensão gênero e políticas públicas.

A construção de uma abordagem quantitativa e multissetorial da situação da mulher, relevante para os que devem tomar decisões práticas na condução das políticas públicas, esbarra na compartimentação das pesquisas, com objetos e metodologias diferentes, e na própria padronização das ações públicas, cujos registros são adequados às condições específicas de reprodução do objeto de sua ação, mas esses critérios comprometem a comparação com outros registros, que, por sua vez, apresentam as mesmas características, de aspectos interferentes na vida das pessoas e sobretudo das mulheres.
Na exploração dos microdados oriundos das pesquisas quantitativas e informações fornecidas pelos registros administrativos, procurou-se estabelecer os seguintes critérios comparativos intersetoriais: recorte de idade, valendo-se de cruzamentos de variáveis com comportamento diferenciado para cada ciclo de vida e inserção social, pela natureza substantiva do fenômeno ou do programa setorial de política pública, a fim de fornecer uma visão multidimensional das populações-alvo; recorte espacial pela agregação dos dados para Estado, regiões administrativas e municípios, com algumas informações de saúde apresentadas por Direção Regional de Saúde - com o objetivo de diagnosticar tendências distintas na reprodução das relações de gênero e regiões prioritárias de intervenção e definir ações públicas que podem ser implementadas por iniciativas regionais, prefeituras, conselhos municipais da condição feminina e comunidades.

Na determinação de potencializar a relação entre produtores (Fundação Seade) e usuários de estatísticas (CECF), adotou-se um modelo de recuperação de informações flexível e amigável para garantir o acesso de usuários que guardam entre si naturezas diferentes: de formação no manuseio de estatísticas; de interesse ou motivação com fins individuais ou coletivos; demandas de informações básicas ou mais desagregadas, para grandes aglomerações ou localizadas espacialmente, de utilização imediata, ou, ainda, uma série histórica para uma reflexão mais profunda. Assim, o sistema de recuperação de informações contém: banco de tabelas, que oferece um conjunto de indicadores que retratam a realidade captada no tempo e no espaço, a fim de fornecer informações previamente elaboradas; acesso de dados numéricos selecionados em tabelas, - resultado de um cruzamento, com intuito de um recorte mais restrito no enfoque do plano tabular; banco de variáveis para que o usuário possa no espaço e no tempo desejados criar seu próprio plano tabular; mecanismos de localização das informações disponíveis com lista dos temas e assuntos, índice alfabético dos títulos de tabelas e variáveis e índice de palavras-chave.

\section{Algumas Observações Empíricas}

Ao agregar informações dispersas e fragmentadas das mais diferentes fontes de dados, descortina-se um mundo de reflexão em cada área temática, e, ao apresentar um conjunto de variáveis por municípios, abrem-se caminhos para o fortalecimento de ações de gênero em âmbito local. Para efeito deste artigo, alguns indicadores foram 
analisados para explicitar as tendências observadas, na última década, na situação das mulheres no Estado.

As tendências observadas no comportamento demográfico da população feminina são subsídios importantes para o planejamento de políticas públicas em setores, como saúde, educação, lazer, entre outros, pois implicam alterações nas demandas da população. A pirâmide etária, que ilustra, ao mesmo tempo, a distribuição da população por sexo e grupos de idade, vem, desde 1991, apresentando um estreitamento devido à redução da fecundidade e um alargamento de seu topo, em conseqüência do aumento da sobrevida da população, indicando crescimento da parcela mais velha da população. Essas mudanças alteram o formato da representação, ou seja, dentro de alguns anos, a estrutura da população por sexo e idade se assemelhará mais a um barril que a uma pirâmide. As Regiões Administrativas de Registro e de São José do Rio Preto representam os extremos neste processo de mudança. Em 1991, a pirâmide etária de Registro possuía uma base mais larga, afunilando-se à medida que alcançava o topo, o que indica uma estrutura mais jovem, enquanto a de São José do Rio Preto, em 2000, apresentava estrutura mais envelhecida, pois o afunilamento da base já era percebido há três qüinqüênios e a parte correspondente à população idosa é maior. De fato, o crescimento do segmento de idosos é uma tendência generalizada não só no país, como no Estado de São Paulo, em que a população com mais de 60 anos correspondia a 7,7\% do total em 1991, passando a $9 \%$ em 2000. Nessa faixa etária, o contingente feminino possui participação superior, por causa da sobrevivência maior. Assim, em 2000, as mulheres idosas respondiam por quase $10 \%$ da população feminina, enquanto os homens idosos representavam $9 \%$ da masculina.

Se alguns indicadores na área de saúde e direitos reprodutivos reafirmam tendências já bastante conhecidas, eles são valiosos para qualificar o ritmo e a distribuição espacial dessas tendências. Como é o caso da redução da fecundidade, cujo ritmo foi mais lento na década de 90 , mas chegando em 2000 a 2,16 filhos por mulher, muito próxima ao nível de reposição. Das 15 regiões administrativas, dez já registravam fecundidade inferior ao da reposição. A RA de São José do Rio Preto apresenta a menor fecundidade do Estado (1,64 filho por mulher), muito próxima ao nível observado em diversos países europeus, enquanto a de Registro possui a maior (2,71 filhos por mulher).

A gravidez na adolescência, fenômeno bastante conhecido, indica crescimento preocupante: no Estado, as mães adolescentes correspondiam a $16,3 \%$ da totalidade dos nascimentos ocorridos em 1990, aumentando para 18,8\% em 1995 e para 19,2\% em 2001. Em outros termos, aproximadamente em cada mil adolescentes de 15 a 19 anos, 75 tiveram filhos na década de 90.

A esperança de vida ao nascer da população paulista aumentou de 69 para 71 anos, entre os censos de 1991 e 2000, fruto da diminuição da mortalidade. As mulheres ainda registram uma esperança maior $(75,6$ anos) em relação à dos homens (66,8 anos) com uma diferença de quase nove anos. Isso se deve a vários fatores, mas destaca-se a elevada mortalidade masculina por violência, que provoca o crescimento da sobremortalidade masculina na população de jovens e adultos.

$\mathrm{Na}$ análise dos determinantes por sexo da mortalidade, no Estado, verificam algumas novas tendências: as doenças do aparelho circulatório eram a primeira causa de morte nos triênios 1993-95 para mulheres e homens. Já no triênio 1999-01 permanece a mesma causa para as mulheres, passando os homicídios a ser a primeira causa para a população masculina. Quando se comparam as taxas de mortalidade de homens e mulheres, nota-se que em todas as regiões do Estado as taxas masculinas são aproximadamente $50 \%$ maiores que as femininas. Essa diferença deve-se principalmente às altas taxas por causas externas entre os homens.

Para as mulheres, o segundo agrupamento mais freqüente como causa de morte corresponde aos cânceres, sendo o de mama o que possui as maiores taxas (14,5 por $100 \mathrm{mil}$ mulheres $)^{4}$ e no período 1980 a 2001 , houve um aumento de $60 \%$ desse tipo de câncer. O câncer do colo do útero, doença passível de ser prevenida, tem apresentado, no Estado de São Paulo, taxas de mortalidade inalteradas desde 1980, em torno de 4,5 por 100 mil mulheres, número bastante alto quando comparado com os dos países desenvolvidos. ${ }^{5}$ É importante lembrar o aumento da mortalidade por Aids entre as mulheres; essa doença representa a principal causa de morte da população feminina entre 15 e 44 anos e, ao incidir predominantemente na população em idade reprodutiva, a Aids tem assumido um papel desestabilizador nos níveis de mortalidade feminina.

A tendência à "cirurgificação" dos eventos reprodutivos, em especial a prática de partos cesáreos, com taxas de 51,6\% em 1995 e 49,2\% em 2001, continua pouco declinante no conjunto do Estado e diferenciando-se espacialmente. São ainda bastante elevados os valores apresentados, em 2001, nas Regiões Regionais de Saúde de Araçatuba, Araraquara, Barretos e São José do Rio Preto 
(superiores a 58,3\%) e nota-se, entre 1995 e 2001, pequena redução dessa prática em regiões como Ribeirão Preto, Campinas e Taubaté. Já a proporção de partos cesáreos, realizados pelo Sistema Único de Saúde - SUS, continua alta $(32 \%)$ e apresenta pequena elevação em relação a 2000 (29\%), diferentemente da tendência de queda observada desde 1995 (41\%). Em 2001, os partos de adolescentes representavam $24 \%$ do total realizado pelo SUS.

Quanto à morbidade hospitalar, o grupo de causas mais freqüentes de internação no SUS da população de 15 anos e mais decorre da gravidez, parto e puerpério que responde por $44 \%$ das internações femininas, incluindo partos normais e cesáreos, e por $27 \%$ do total de internações. $\mathrm{Na}$ diferenciação entre os sexos, destacam-se as causas externas que representam as internações vinculadas a acidentes e violências e que, em números absolutos, são, em 2001, 2,5 vezes maiores entre os homens.

A morbidade por Aids, apesar de ter uma incidência maior para os homens, apresenta situação preocupante em virtude do aumento de casos, expresso na vertiginosa diminuição da relação de casos masculinos/femininos que, em 1985, era de 27/1, passou para 5/1, em 1991, e desde 1997 é de 2/1. A principal forma de transmissão para as mulheres é a heterossexual, que, em 2000, respondia por $89 \%$ dos casos femininos com transmissão definida. A expansão do número de casos deu-se também em termos territoriais: dos 132 municípios com casos femininos de Aids notificados, em 1991, o Estado passou a ter 255, em 2000 .

A morbidade percebida pelos indivíduos, medida pela condição de saúde, inatividade e prevalência de doenças crônicas, evidenciam diferenciais por sexo e idade e indicam diferentes graus de necessidades e de demandas por serviços de saúde. Em 1998, segundo o Suplemento Saúde da Pesquisa Nacional por Amostra de Domicílios PNAD, a proporção de pessoas que referiram melhor condição de seu estado de saúde cai gradativamente conforme a faixa etária, passando de $91,8 \%$, entre os adolescentes e jovens (de 15 a 24 anos), para $45 \%$, entre os idosos com 65 anos e mais. Os homens referem, em média, melhor situação $(81,6 \%)$ que as mulheres $(75,2 \%)$.

Também bastante conhecido, o fenômeno, observado sobretudo no último quarto do século XX, de aumento contínuo da presença feminina no mercado de trabalho não é acompanhado de melhores relações de trabalho, persistindo, ainda, desigualdades de tratamento entre homens e mulheres, e a mais evidente é a discriminação salarial. Basta observar, no Estado de São Paulo, a distribuição dos salários mais elevados registrados em 2001: eles se encontram entre as mulheres empregadas no setor de serviços, com 40 a 49 anos de idade, percebendo em média $\mathrm{R} \$ 1.346,61$ e entre os homens, da mesma faixa etária, e ocupados na indústria, totalizando R \$ 2.107,21.

Apesar do ingresso de mulheres em ocupações que, até há pouco tempo, eram monopólio dos homens e da crescente participação feminina no emprego industrial e em ocupações de direção e planejamento, nichos ora privilegiados do emprego masculino, sua maior representação se dava no setor de serviços, correspondendo a $24,8 \%$ do total dos empregados, em 2001 , e somente $6,5 \%$ e $6,1 \%$, respectivamente, no comércio e indústria. Já os homens respondiam por $27,1 \%, 17,5 \%$ e $10,5 \%$ do empregado, nos mesmos setores. No entanto, cresceu a proporção de mulheres ocupadas com vínculo não formalizado, representando, no mesmo período, cerca de $40 \%$ dos ocupados, os serviços domésticos são fonte importante de inserção ocupacional.

Conforme os dados dos censos demográficos para o Estado de São Paulo, houve aumento do número de mulheres chefes de domicílio: em 2000, elas eram 24\% do total; em 1991 esse percentual era de 17\%. Identificouse, ainda, a persistência de acentuada desigualdade de rendimentos, com elevada proporção de chefes de domicílio que recebiam até dois salários mínimos.

Vale destacar que o valor do rendimento feminino, em proporção ao masculino, tende a mostrar menor desigualdade nos municípios menos dinâmicos economicamente, encobrindo situações de extrema necessidade de renda, enquanto as maiores diferenças são constatadas nos municípios-pólo, que são fonte da oportunidades de trabalho mais diversificadas tanto para homens quanto para mulheres e também de maiores rendimentos médios.

Apesar de serem as grandes beneficiárias do processo de universalização do acesso ao ensino fundamental, mesmo em declínio entre os períodos censitários, as mulheres apresentam taxas de analfabetismo ligeiramente superiores a dos homens. Em 1991, registraram-se taxas de analfabetismo das mulheres de 15 anos e mais de $11,8 \%$ e para os homens de $8,6 \%$, em $2000,7,5 \%$ e $5,7 \%$, respectivamente.

É interessante observar que, em 1991, as mulheres apresentaram taxas de analfabetismo ligeiramente inferiores a dos homens nos seguintes grupos etários:15 a 19 anos $(2,5 \%), 20$ a $24(3,8 \%), 25$ a $29(4,6 \%)$; no grupo de 30 a 39 anos, delineou-se a inversão desse quadro, taxa de $6,9 \%$ para as mulheres e 5,8\% para os homens, atingindo no 
grupo de idade de 60 anos e mais valores de $36,1 \%$ e $23,9 \%$, respectivamente.

Em 2000, diminui o analfabetismo em todos os grupos etários: nas faixas de 15 a 19, 20 a 24 e 25 a 29 anos, as taxas para as mulheres eram de $1,1 \%, 1,7 \%$ e $2,4 \%$ e para os homens de $1,7 \%, 2,6 \%$ e 3,3\%. Já no grupo de 30 a 39 anos, diferentemente do observado em 1991, verifica-se valor menor para as mulheres $(3,8 \%)$ do que para os homens $(4,3 \%)$, ocorrendo a reversão de tendência apenas na faixa etária de 40 a 49 anos, em que se observaram taxas de $6,6 \%$ para as mulheres e de $5,3 \%$ para os homens. $\mathrm{Na}$ população idosa - 60 anos e mais -, as taxas eram de $26,3 \%$ para o contingente feminino e de $17,2 \%$ para o masculino.

Ao analisar a instrução da população de 10 anos pelos recortes sexo e raça/cor, evidenciam algumas desigualdades: em 2000, 17,7\% das mulheres brancas e 12,5\% das negras tinham 11 anos de estudo; entre os homens, os percentuais são de $16,6 \%$ para os brancos e $10,9 \%$ para os negros. A categoria de 12 anos e mais de estudo escancara o quadro de desigualdade racial existente no Estado, uma vez que, apenas 3,1\% de mulheres e $2,7 \%$ dos homens negros atingiram esse patamar de escolaridade em contrapartida aos $12,7 \%$ de mulheres e $13 \%$ de homens brancos.

Reforçar a promoção da igualdade de gênero e a melhoria da condição da mulher passa pela avaliação dos programas de atendimento à criança de 0 a 6 anos, sobretudo, no Brasil, quando a Constituição de 1988 e a Lei de Diretrizes e Bases de 1996 estabeleceram competências e diretrizes para a educação infantil em colaboração com os Estados e municípios. Os dados do Censo de 2000, que informam o atendimento de crianças nessa faixa etária, indicam sua pouca abrangência: em mais da metade dos municípios paulistas (379) a rede de creches e de educação infantil cobrem entre $20,1 \%$ e $40 \%$ das crianças de 0 a 6 anos e apenas 53 deles atendem mais de 50\%.

Nos últimos anos, observa-se que os registros de crimes de natureza sexual possuem certa estabilidade em sua magnitude. Isso pode significar tanto a existência de um determinado padrão de incidência na sociedade paulista com relação aos crimes sexuais, como pode refletir mais a capacidade do Estado em captar e processar os crimes desta natureza do que o real movimento dessa criminalidade. A taxa de estupros/tentativas por 100 mil mulheres, crimes que juridicamente vitimam somente as mulheres, passou, no Estado de São Paulo, de 29,18 em 1997 para 26,90 em 2001. As Regiões de Governo de São Carlos,
Adamantina e Marília apresentaram as menores taxas médias de estupros/tentativas, por 100 mil mulheres, entre 1997 e 2001, em contrapartida, as Regiões de Governo de Registro, Caraguatatuba e Itapeva registraram as maiores taxas médias no período. Apesar de termos somente 126 Delegacias de Defesa da Mulher para 645 municípios, elas continuam ocupando papel de destaque no atendimento de vítimas de violência sexual, pois são as que mais processam, proporcionalmente, casos dessa natureza. Afinal, trabalhando concomitantemente aos distritos policiais, elas são responsáveis por quase $50 \%$ dos registros policiais relativos aos crimes de estupros existentes no Estado.

As informações que têm por base os dados do sistema de mortalidade, indicam que em 2001 o grupo de mortes por causas externas para a população feminina com mais de 10 anos ocupa o quinto lugar entre as causas de morte mais freqüentes, com um dado surpreendente: considerando-se o período de 1980 e 2001, o índice de homicídios aumentou 120\%. Para os triênios 1993-95 e 1999-01, as taxas de homicídio apresentaram elevação de 4,5 para 5,6 por 100 mil mulheres, reproduzindo o fenômeno observado para o sexo masculino. Ainda em relação aos homicídios, sua distribuição em relação ao total de óbitos, passa de $4,4 \%$ para $6,4 \%$ para o sexo feminino no Estado e de $19,7 \%$ para $29,6 \%$ para o sexo masculino.

A participação das mulheres nas candidaturas partidárias continua extremamente desigual mesmo com a introdução da política de cotas no processo eleitoral, que, desde 1997, prevê que partido ou coligação deverá reservar o mínimo de $30 \%$ e o máximo de $70 \%$ para candidaturas de cada sexo nas eleições para a Câmara dos Deputados, Câmara Legislativa, Assembléias Legislativas e Câmaras Municipais.

Nas eleições para deputados federais de 2002, o número de candidaturas femininas aumentou $27,9 \%$ em relação às eleições anteriores. Em 1998, dos 30 partidos que apresentaram candidatos, nove não registraram candidaturas femininas e, em 2002, oito não o fizeram. Mesmo não atingindo a indicação da política de cotas, alguns partidos tiveram melhoria dessa participação entre as duas eleições, como PFL, PV, PCB, PDT, PAN, PTB, PSTU, PSD, enquanto outros reduziram-na, como PSDB, PMDB, PT e Prona. Outros partidos aumentaram o número total de candidatos, mas não melhoraram a proporção da representação feminina entre as candidaturas, como, por exemplo, o PSB. Dessa forma, somente quatro mulheres se elegeram deputadas federais, em 1998 e seis, em 2002. 
Dos 1.465 candidatos à Assembléia Legislativa do Estado de São Paulo em 2002, 242 eram mulheres, representando $15,5 \%$ do total. Em termos absolutos, houve aumento significativo de $37,5 \%$ na participação das mulheres entre as duas últimas eleições legislativas estaduais, uma vez que, em 1998, elas totalizavam 176. Quanto à participação relativa das mulheres nos partidos, em 2002, somente o PSDC e o PCO, cuja expressão política é bastante reduzida, cobriram a cota de $30 \%$ com candidaturas femininas. Também são os partidos de pequeno porte que têm participação feminina de candidaturas entre $20 \%$ e $30 \%$. Entretanto, observa uma relação inversa entre volume de candidatos e participação feminina: PT, PMDB, PSDB, PDT, PSB, PPS, PMDB e PSDB estão entre os partidos com maior número de candidatos e com cotas de candidatura feminina inferiores a $20 \%$. As únicas exceções foram o PV e o PTB, que apresentaram cotas entre $20 \%$ e $30 \%$. Observa-se, entretanto, certa correlação entre mulheres eleitas para deputadas estaduais e força política de seu partido: em 2002, foram eleitas dez mulheres (elas eram sete no período legislativo de 1997/2002), e três delas são filiadas ao PSDB e três, ao PT.

Mesmo não atingindo as cotas femininas previstas de candidaturas por partido, é maior a participação das mulheres na disputa pelo poder legislativo municipal comparativamente às outras Câmaras. Em 2000, 13.317 mulheres candidataram-se a cargos de vereadores dos municípios paulistas, representando $20,07 \%$ do total. Dos 30 partidos que concorreram às câmaras municipais, 13 registraram proporções de participação feminina entre $18 \%$ e $26 \%$. A correlação aumenta entre os partidos com maior representação em termos absolutos de candidaturas femininas e sua expressão política, tais como PSDB, PMDB, PFL e PTB, que agregaram quase $40 \%$ das candidaturas femininas. São esses mesmos partidos que elegeram proporcionalmente mais vereadoras: das 812 eleitas em 2000, quase $60 \%$ são filiadas ao PSDB, PMDB, PTB e PFL. É interessante notar que alguns partidos melhoraram sua participação feminina em relação à masculina entre o momento das candidaturas e das eleições. As proporções de candidatas e de eleitas foram, respectivamente, de: $11,0 \%$ e $21,6 \%$ no PSDB; $9,8 \%$ e $14,2 \%$ no PMDB; $9,2 \%$ e $11,5 \%$ no PTB; $6,5 \%$ e $9,1 \%$ no PT; $6,9 \%$ e $8,3 \%$ no PPB. Esses resultados apontam que: os canais de participação das mulheres aos postos legislativos são mais permeáveis quando se trata de eleições locais, em que os custos das campanhas eleitorais são menores; a dispersão de votos entre as candidaturas femininas é provavelmente menor do que nas eleições para deputados; e, finalmente, há uma aproximação maior entre candidatas e eleitores 0 que pode abrandar as resistências culturais contra o voto feminino.

\section{NOTAS}

Este artigo foi possível graças aos trabalhos setoriais desenvolvidos no âmbito do projeto sob minha coordenação dos seguintes analistas da Fundação Seade: Catarina Guarnieri Silverio, Cecília Polidoro Mameri, Eliana B. Trindade Bordini, Guiomar de Haro Aquilini, Lúcia Mayumi Yazaki, Paula Montagner, Renato Sérgio de Lima, Rosileide de Lima Rosendo e Zilda Pereira da Silva.

1. Resoluções adotadas pela IV Conferência Mundial das Nações Unidas sobre a Mulher, 1995; Relatório Geral sobre a Mulher na Sociedade Brasileira/1994; Relatório Nacional Pequim + 5 apresentado à Sessão Especial da Assembléia das Nações Unidas "Mulher 2000: Igualdade de Gênero, Desenvolvimento e Paz para o Século XXI"; Programa de Ação Regional para as Mulheres da América Latina e Caribe, 1995-2001, aprovado pela Cepal durante a VI Conferência Regional sobre a Integração da Mulher no Desenvolvimento Econômico e Social da América Latina e Caribe/1994; protocolos de cooperação assinados pelo CECF e secretarias estaduais para a implementação de políticas públicas referentes a educação, saúde, trabalho, segurança pública, administração penitenciária, justiça e defesa da cidadania.

2. A pobreza individual ou familiar não se esgota no montante de renda disponível para atender aos gastos de consumo, mas se expressa também pelas condições de moradia, de acesso diferenciado ao sistema educacional e aos serviços de saúde. Embora a insuficiência de renda seja a face mais visível do fenômeno, políticas de combate ao problema devem intervir em suas várias dimensões. A abordagem da pobreza como fenômeno multissetorial é uma preocupação norteadora da Pesquisa de Condições de Vida - PCV, cujos resultados para o Estado de São Paulo estão disponíveis na Fundação Seade (Fundação Seade, 1992).

3. Declaração Universal dos Direitos Humanos, 1948; Convenção dos Direitos Políticos, 1952 e 1960; a Convenção para a Eliminação de todas as Formas de Discriminação contra a Mulher, 1979; a Conferência de Nairobi, 1985; a VI Conferência Mundial sobre a Mulher,1995.

4. Essas taxas referem-se ao triênio 1999-01 para o Estado de São Paulo.

5. As taxas de mortalidade por câncer do colo do útero na Itália, Japão e Estados Unidos são respectivamente de $0,8,1,8$ e 2,6 por $100 \mathrm{mil}$ mulheres.

\section{REFERÊNCIAS BIBLIOGRÁFICAS}

ABRAMOWICZ, A. A menina repetente: o duplo fracasso. 1991. Dissertação (Mestrado) - Pontifícia Universidade Católica, São Paulo, 1991.

ALVES, J.E.D. Transição e fecundidade e relações de gênero no Brasil. Tese (Doutorado) - Cedeplar-UFMG, Belo Horizonte, 1994.

ALVES, E.L.G.; AMORIM, B.M.F.; CUNHA, G.H.M. Emprego e ocupação: algumas evidências do mercado de trabalho de gênero na Grande São Paulo - 1988/1995. Brasília: Ipea, dez. 1996. Mimeografado.

BACHA, A.M.; GRASSIOTO, O.R. Aspectos éticos das práticas abortivas clandestinas. Revista Bioética, v.2, n.1, 1994. Disponível em: $<$ www.cfm.org.br $>$. 
BRUSCHINI, C. O uso de abordagens quantitativas em pesquisas sobre relações de gênero. In: COSTA, A.O.; BRUSCHINI, C. (Orgs.) Uma questão de gênero. Rio de Janeiro: Rosa dos Tempos/São Paulo, Fundação Carlos Chagas, 1992.

BRUSCHINI, M.C.A. Trabalho das mulheres no Brasil - continuidades e mudanças no período 1985-1995. São Paulo: Fundação Carlos Chagas/DPE, 1998.

CASAS, M.I.; SILVA, T. da; LOFORTE, A.; MEJIA, M. Perfil de gênero da província de Nampula. Relatório Final. Saúde numa Perspectiva de Gênero. Maputo-Nampula, out. 1998, cap. 6.

CEPAL - COMISSÃO ECONÔMICA PARA A AMÉRICA LATINA E CARIBE. Disponível em: <www.eclac.cl/mujer>. Acesso em: 2001.

COSTA, L.B. Absorção diferencial da mulher no mercado de traba1ho. In: X ENCONTRO NACIONAL DE ESTUDOS POPULACIONAIS. 1996, Caxambu. Anais... Caxambu: Abep, v.1, 1996. p.559567.

FUNDAĈ̃O SEADE. Mulher \& trabalho. São Paulo: Fundação Seade - Agência Canadense para o Desenvolvimento Internacional Conselho Estadual da Condição Feminina, 2002 (vários números).

. Mulher \& trabalho. São Paulo: Fundação Seade - Agência Canadense para o Desenvolvimento Internacional - Conselho Estadual da Condição Feminina, 2000 (vários números).

. 20 anos no ano 2000. Estudos sociodemográficos sobre a juventude paulista. São Paulo, 1998a.

- Avaliação da qualidade dos dados da declaração de nascimentos em 1997. Sistema de acompanhamento contínuo da mortalidade infantil. Mortalidade materna e características do recém-nascido. São Paulo, 1998b.

Mulher \& trabalho. São Paulo: Fundação Seade - Agência Canadense para o Desenvolvimento Internacional - Conselho Estadual da Condição Feminina, 1997 (vários números).

Pesquisa de condições de vida - Uma abordagem multissetorial. São Paulo, 1992.

GALVÃO, L.; DIAZ, J. (Orgs.). Saúde sexual e reprodutiva no Brasil. Dilemas e desafios. São Paulo, Hucitec/Population Council, 1999.

GOLDANI, A.M. Família, relações de gênero e fecundidade no Nordeste do Brasil. In: BEMFAM. Fecundidade, anticoncepção e mortalidade infantil. Pesquisa sobre Saúde Familiar no Nordeste 1991. Rio de Janeiro, 1994. p.57-80.

Famílias e gêneros: uma proposta para avaliar (des)igualdades. In: XII ENCONTRO NACIONAL DE ESTUDOS POPULACIONAIS. Caxambu: Abep, 2000. (CD-ROM).

GOMEZ GOMEZ, E. Introducción. In: GOMEZ GOMEZ, E. (Ed.). Género, mujer y salud en las américas. Washington D.C.: Organización Panamericana de la Salud, 1993. (Publicación Científica, 541).

HEILBORN, M.L. Cidadania para as mulheres. Revista Ciência Hoje, v.5, n.28, p.13-15, jan./fev. 1987. (Violência - Encarte Especial).

HIRATA, H.; KERGOAT, D. A classe operária tem dois sexos. Revista Estudos Feministas. Rio de Janeiro, CIEC/UFRJ, n.1, p.93-100, 1994
LEONE, E.T. Renda familiar e trabalho da mulher na Região Metropolitana de São Paulo: anos 1981, 1990 e 1995. In: SEMINÁRIO TRABALHO E GÊNERO: MUDANÇAS, PERMANÊNCIAS E DESAFIOS. Campinas, Abep, abr. 1998. Mimeografado.

MADEIRA, F.R. (Org.). Quem mandou nascer mulher? Rio de Janeiro: Rosa dos Tempos/Unicef, 1996.

MALHEIROS, S.M. A politica de cotas por sexo. Um estudo das primeiras experiências no legislativo brasileiro. Brasília: Centro Feminista de Estudos e Assessoria - Cfemea, 2000.

MOREIRA, M. de M. Relações de gênero e fecundidade: Nordeste, 1991. In: BEMFAM, Fecundidade, anticoncepção e mortalidade infantil. Pesquisa sobre Saúde Familiar no Nordeste 1991. Rio de Janeiro, 1994. p.81-91.

OLIVEIRA, E.M.; BARRETO, M. Engendrando gênero na compreensão das lesões por esforços repetitivos. Saúde e Sociedade. São Paulo, v.6, n.1, jan./jul. 1997.

OLIVEIRA ARAÚJO, C.M. Cidadania incompleta: o impacto da lei de cotas sobre a representação política das mulheres no Brasil. 1999. Tese (Doutorado) - Instituto de Filosofia e Ciências Sociais, UFRJ, Rio de Janeiro, 1999.

ONU/CEPAL. Indicadores de género para el seguimiento y la evaluación del Programa de Acción Regional para las Mujeres de América Latina y el Caribe, 1995-2001 y la Plataforma de Acción de Beijing. Santigo do Chile, 1999. Disponível em: $<$ www.eclac.org $>$.

ONU/CNDM - Conselho Nacional dos Direitos da Mulher. IV Conferência Mundial sobre a Mulher. Beijing, China-1995. Rio de Janeiro: Editora da Fiocruz, 1996.

PIMENTEL, S.; SCHRITZMEYER, A.L.P.; PANDJIARJIAN, V. Estupro: crime ou "cortesia"? Abordagem sociojurídica de gênero. Porto Alegre: Sérgio Antonio Fabris, 1998. p.23-24.

RELATÓRIO Nacional Pequim +5 apresentado à Sessão Especial da Assembléia Geral das Nações Unidas "Mulher 2000: Igualdades de Gênero, Desenvolvimento e Paz para o Século XXI" (Pequim +5), Nova York, jun. 2000. Disponível em: <www.brasil.gov.br/ minst_set.htm>.

SEGNINI, L.R.P. Desemprego, terceirização e intensificação do trabalho nos bancos brasileiros. In: ROCHA, M.I.B. (Org.). Trabatho e gênero - Mudanças, permanências e desafios. São Paulo: Editora 34, 2000.

SIMÕES BARBOSA, R.H. Aids e saúde reprodutiva: novos desafios. In: GIFFIN, K.; COSTA, S.H. (Orgs.). Questões da saúde reprodutiva. Rio de Janeiro: Editora da Fiocruz, 1999.

WAJNMAN, S.; RIOS NETO, E.L.G. Quantas serão as mulheres: cenários para atividade feminina. In: ROCHA, M.I.B. (Org.). Trabalho e gênero: mudanças, permanências e desafios. São Paulo: Editora 34, 2000

Maria Cecílía Comegno: Socióloga. Coordenadora de Projetos de Gênero na Fundação Seade. Foi responsável pela Diretoria Adjunta de Produção de Dados desta Fundação (ccomegno@seade.gov.br). 